\title{
Characterisation of activated lymphocytes in the peripheral blood of patients with rheumatoid arthritis
}

\author{
S. D. CARTER, * P. A. BACON, AND N. D. HALL \\ From the Royal National Hospital for Rheumatic Diseases, Bath, and Pharmacology Group, School of \\ Pharmacy and Pharmacology, University of Bath
}

SUMMARY The extent and nature of lymphocyte activation in the circulation in rheumatoid arthritis (RA) was investigated. Peripheral blood lymphocytes (PBL) from RA patients and healthy controls were separated into a number of discrete fractions by density in discontinuous Ficoll density gradients. Low density (activated) lymphocytes were found at significantly higher levels in RA, particularly in patients with clinically active disease. Conversely, patients with clinically inactive RA had normal levels of activated lymphocytes. Lymphocyte populations within the Ficoll gradient fractions were detected by E rosettes, staining for surface Ig, and by different avidities of EA binding. The activated population in RA was shown to be relatively depleted of $T$ cells, enriched in surface Ig-bearing lymphocytes, and depleted of lymphocytes with high avidity EA binding. The evidence suggests that many of the activated PBL in RA are B blasts.

The elegant thoracic duct drainage (TDD) studies of Paulus et al. ${ }^{1}$ have suggested an important role for circulating lymphocytes in the immunopathogenesis of rheumatoid arthritis (RA). These authors attributed the clinical improvement observed in their patients to suppression of the immune response following TDD. However, Ueo et al. ${ }^{2}$ have shown that the clinical improvement resulting from TDD may be due to an imbalance of the circulating and marginated pools of lymphocytes resulting in an accelerated migration of lymphocytes from inflamed sites in synovial tissue to the blood stream which regresses once TDD is discontinued. Thus, a role for circulating lymphocytes in the pathogenesis of RA has not been proved unequivocally by lymphatic drainage studies. Moreover, this issue is complicated by the varying recirculatory abilities of the different cell types resulting from activation of lymphocytes. While small lymphocytes may recirculate freely, very few, if any, blast cells or plasma cells recirculate from blood to lymph. ${ }^{3}$ Such activated lymphocytes may be of particular interest in RA, as they either constitute or become the primary effector cells of the immune response and have been found at high levels in the synovial

Accepted for publication 2 July 1980

*Present address: Department of Immunology, University Hospital, Queen's Medical Centre, Nottingham.

Correspondence to Dr N. D. Hall, Royal National Hospital for Rheumatic Diseases, Bath BA1 1RL. membrane, ${ }^{4}$ synovial fluid, ${ }^{5}$ and peripheral blood of rheumatoid patients. ${ }^{67}$ Circulating blast cells will incorporate increased amounts of ${ }^{3} \mathrm{H}$-thymidine, ${ }^{8}$ and their levels are also associated with disease activity. $^{6}$

The nature and function of the circulating blasts in RA have not been elucidated. This is largely due to the relatively low percentage of these cells within the total lymphocyte population. Activated lymphocytes in the rheumatoid synovium have received more attention, and it has been shown that, although most RA synovial membrane lymphocytes are $\mathrm{T}$ cells, ${ }^{9} \mathrm{a}$ disproportionately high number of synovial blasts are B blasts and plasma cells. ${ }^{10}$

Studies of lymphocyte subpopulations in the blood have looked at the T and B cell markers ${ }^{11-13}$ or Fc receptors ${ }^{14}{ }^{15}$ of the whole lymphoid population without attempting to analyse the nature of the activated lymphocytes. To this end a means of enriching populations of lymphocytes activated in vivo, utilising their decreased density in Ficoll gradients, has been developed ${ }^{16}$ and employed in this study to permit further analysis of peripheral blood blasts in RA.

\section{Patients and methods}

Forty-seven patients with definite RA were studied (28 females and 19 males) who were receiving nonsteroidal anti-inflammatory therapy or analgesics. 
Patients who were receiving, or had been receiving during the month prior to testing, steroids, cytotoxic drugs, or penicillamine were excluded. Clinical assessments of disease activity were made by an independent observer. Thirty-two age- and sexmatched healthy subjects were also studied.

\section{DENSITY FRACTIONATION OF LYMPHOCYTES}

Density gradient separation of blood lymphocytes was performed as previously described. ${ }^{16}$ Briefly, mononuclear leucocytes were prepared from peripheral blood by Ficoll/Paque separation, ${ }^{17}$ the monocytes depleted by adherence to glass, and the remaining lymphocytes ( $>99 \%$ ) separated in discontinuous Ficoll $(16-30 \%)$ density gradients at $3000 \mathrm{~g}$. The interfaces of the gradient layers were harvested and the cells washed and counted. The cells in each fraction were expressed as a percentage of the total number recovered from the gradient. Lymphocytes from patients and age- and sexmatched controls were separated in parallel gradients.

\section{E ROSETTE FORMING CELLS}

Lymphocytes from the gradient interfaces were washed 3 times with phosphate-buffered saline (PBS), adjusted to $2 \times 10^{6} \mathrm{ml}^{-1}$, and $200 \mu 1$ of this suspension were mixed with $200 \mu l$ washed sheep red blood cells (SRBC) containing 10\% new born calf serum. After $10 \mathrm{~min}$ incubation at $37^{\circ} \mathrm{C}$ the cells were pelleted at $200 \mathrm{~g}$ and incubated at $4^{\circ} \mathrm{C}$. The rosettes were resuspended on a rotary turntable and the lymphocytes stained with crystal violet $(0.2 \%)$ before microscopical examination in a Neubauer chamber. A rosetting lymphocyte was counted as one binding 3 or more SRBC.

\section{SURFACE Ig BEARING CELLS}

Peripheral blood lymphocytes were prepared by isopycnic centrifugation and washed 3 times with PBS. Monocytes were removed by incubation at $37^{\circ} \mathrm{C}$ for $45 \mathrm{~min}$ over glass. This procedure also removed labile immunoglobulin on the cell surface. Membrane Ig was stained by incubation with FITC-conjugated antihuman gammaglobulin (Wellcome) at $4^{\circ} \mathrm{C}$ for $60 \mathrm{~min}$. Three washes in PBS were followed by density separation in a Ficoll gradient. Gradient interface fractions were harvested and washed, and the percentage of fluorescent-labelled cells was counted in a Leitz UV microscope.

\section{FC RECEPTOR BEARING CELLS}

These cells were detected by forming rosettes with ox red blood cells (ORBC) coated with rabbit IgG anti-ORBC. The IgG fraction of rabbit anti-ORBC had been purified by affinity chromatography to protein A-Sepharose CL-4B and subsequent elution with $1 \mathrm{M}$ acetic acid. Equal volumes of washed ORBC ( $2 \%)$ in PBS and IgG antibody at titres of $1 / 800$ or $1 / 3200$ were mixed and incubated at $37^{\circ} \mathrm{C}$ for $60 \mathrm{~min}$. The ORBC were washed 3 times with PBS, made up to $1 \%$, and equal volumes $(200 \mu \mathrm{l})$ of coated ORBC and washed gradient interface lymphocytes were mixed, pelleted, and incubated at $4^{\circ} \mathrm{C}$ for $60 \mathrm{~min}$. EA rosettes were determined as for E rosettes.

\section{STATISTICS}

Where applicable the data were analysed for statistical significance by Student's $t$ test (with Yates's correction).

\section{Results}

DENSITY DISTRIBUTION OF LYMPHOCYTES Comparisons of density distribution patterns of blood lymphocytes in RA and controls are shown in Fig. 1a. In both RA and controls the majority, $51 \%$ and $67 \%$ respectively, of the cells were found in dense fraction G. RA patients had significantly more cells than controls in the low density fractions $\mathrm{C}, \mathrm{E}$ $(P<0.01)$, and $D$ and $F(P<0.001)$ and less in $G$ $(P<0.001)$.

The relationship between lymphocyte density distribution and RA disease activity was investigated. Fig. 1b shows the results from groups of clinically active $(n=11)$ and inactive $(n=12)$ patients. Those with clinically active RA had significantly $(P<0.001)$ fewer lymphocytes $(39 \%)$ in fraction $G$ than those with inactive RA $(65 \%)$, with a result that more low density lymphocytes were found in the clinically active patients, notably in fractions $F(P<0.001)$ and $C$ and $E(P<0.02)$. In fact the patients with clinically inactive RA had distribution patterns very similar to those of healthy subjects.

LYMPHOCYTE SURFACE MARKERS IN FICOLL GRADIENT FRACTIONS

Within each set of data in this section the figures represent the percentage positive cells in each gradient fraction. In some subjects there were not enough lymphocytes in the low density fractions for satisfactory surface marker analysis, and hence individual numbers in each experiment are not given. There were usually 10-20 samples assayed per gradient fraction with the exception of fraction A.

The percentage $\mathrm{E}$ rosetting lymphocytes in the gradient fractions are shown in Fig. 2a. It may be seen that more of the dense cells (fraction $G$ ) form E rosettes in both RA patients and controls, $55 \%$ and $62 \%$ respectively, whereas in fraction $\mathrm{B}$ only 


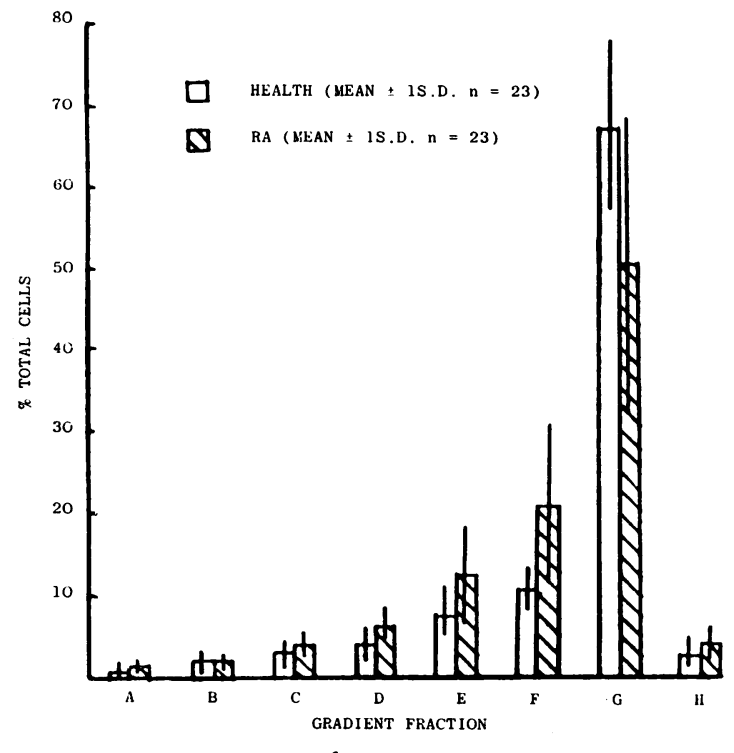

ia

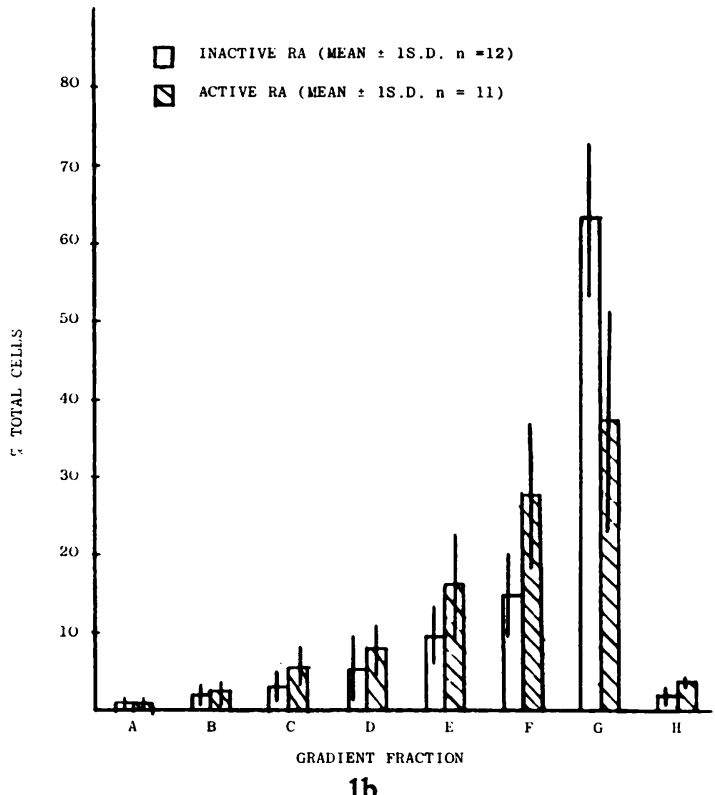

Fig. 1 Lymphocyte density distribution patterns in $R A$. (a) Health and RA. (b) Clinically active and inactive $R A$.

$30 \%$ and $31 \%$ of the cells form $E$ rosettes. There were no statistically significant differences between rheumatoid patients and controls.

The B cell marker, integral membrane immunoglobulin (SIg), shows an opposite trend (Fig. 2b),

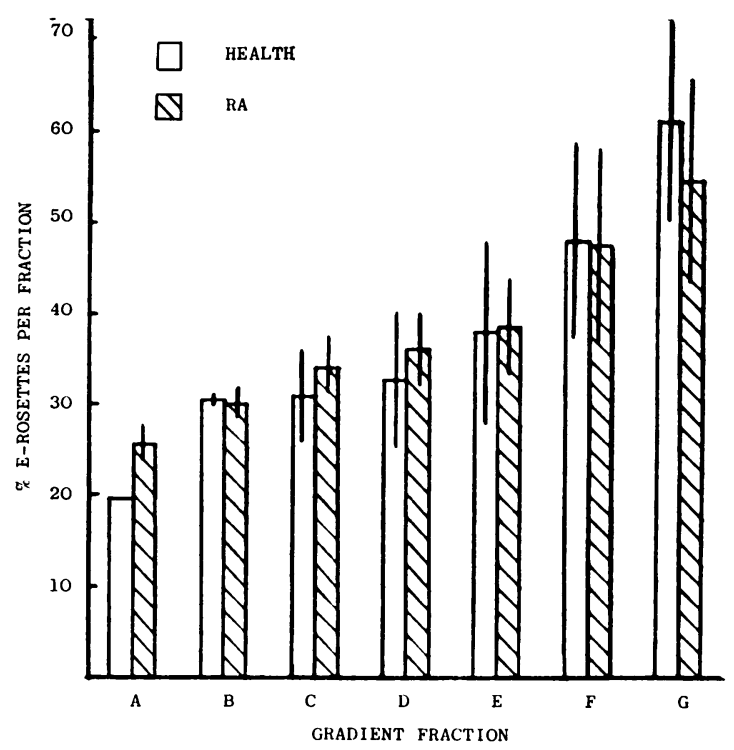

$2 a$

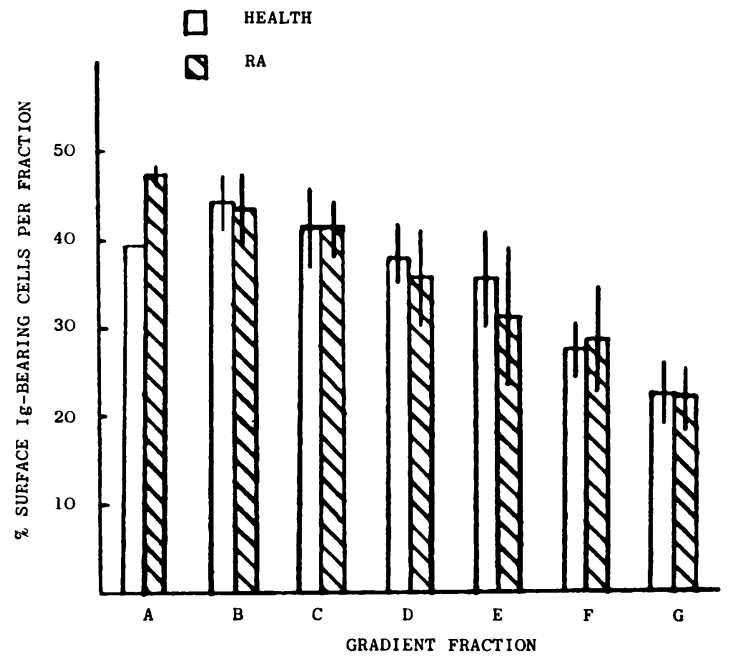

$2 \mathrm{~b}$

Fig. 2 Lymphocyte surface markers in Ficoll gradient fractions in health and $R A$. (a) $T$ cells (E-rosettes). (b) B cells (SIg).

the low density cells having the highest percentages of positively staining cells with decreasing occurrence in the denser fractions. There were no statistically significant differences between RA and controls.

The use of two different IgG concentrations for coating the ORBC in the EA rosetting assay enabled examination of 2 avidities of IgG-FcR binding. At 


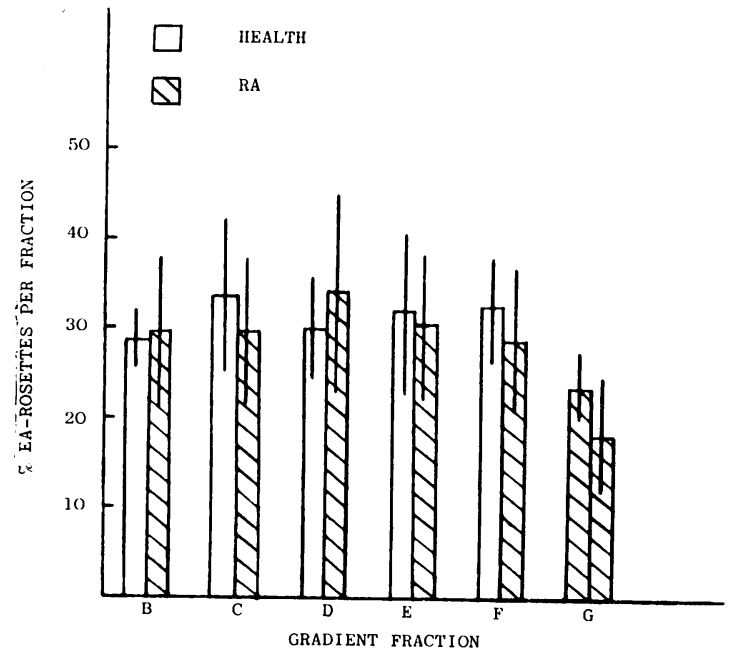

$3 a$

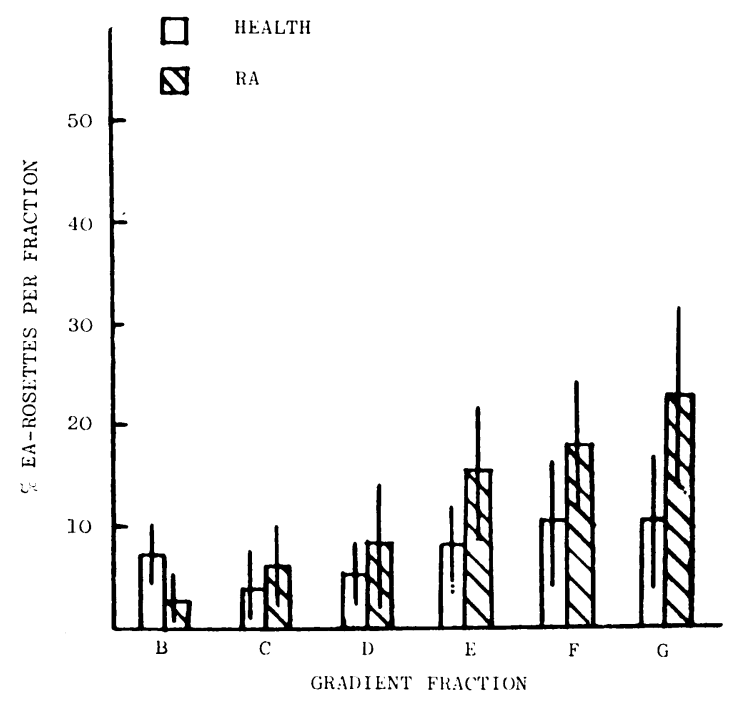

$3 \mathrm{~b}$

Fig. 3 EA binding in Ficoll gradient fractions in health and $R A$. (a) Low + high avidity binding (1/800 titre of coating IgG). (b) High avidity binding (1/3200 titre).

an IgG titre of $1 / 800$ the assay detects high and low avidity binding whereas at $1 / 3200$ only high avidity binding is detectable. ${ }^{15}$ Assaying low + high avidity binding within the gradient fractions (Fig. 3a) showed no specific trend in RA or controls, though there is a marked drop in the percentage EA rosettes formed in the dense fraction $\mathrm{G}$ by comparison with fraction $F$ in controls $(P<0.02)$ and, particularly, in RA $(P<0.005)$.

High avidity EA rosette formation, when $1 / 3200$ titre of IgG anti-ORBC was used, produced as expected far fewer rosettes (Fig. 3b). These lymphocytes were found predominantly in the dense cell fractions of the Ficoll gradient. Rheumatoid patients had significantly more rosetting lymphocytes than controls in fractions $\mathrm{E}(\mathrm{P}<0.05), \mathrm{F}$ $(P<0 \cdot 10)$, and $G(P<0 \cdot 01)$.

\section{Discussion}

In this study we have employed a technique which has enabled us to detect and isolate low density lymphocytes from peripheral blood in RA. There is much evidence from animal experiments that low density lymphocytes contain antigen-activated populations of cells, ${ }^{18} 19$ and we have confirmed a decrease in density in relation to activation of human circulating lymphocytes. ${ }^{16}$ The increased incidence of low density lymphocytes in RA is indicative of increased numbers of activated lymphoid cells in the circulation, supporting the reports of increased immunoblast levels by Bacon et al. ${ }^{6}$ and Delbarre et $a l .{ }^{7} \mathrm{~A}$ decrease in cell density is one of the earliest physical changes associated with lymphocyte activation $^{20}$ and is directly related to changes in the lymphocyte cytoplasmic refractive index in RA, ${ }^{21}$ another indicator of recent cell activation..$^{22}$

The association between disease activity in RA patients and increased numbers of low density lymphocytes is in agreement with reports correlating high levels of immunoblasts in the circulation with clinically assessed disease activity ${ }^{6}$ and high erythrocyte sedimentation rate (ESR). ${ }^{7}$ We have made serial studies of lymphocyte density patterns in rheumatoid patients during treatment with gold and cyclophosphamide, and this appears as a separate publication. ${ }^{23}$

Whether the blasts divide, die, or develop in the circulation or spread the immune response to other tissues, they must be produced in large numbers, as their life in the circulation is only hours ${ }^{24}$ in comparison with the months that small lymphocytes may survive. $^{25}$ The site of activation may be lymph node(s), as is frequently the case in antigenic triggering of proliferation, or synovial tissue itself, which, notably in RA, has many of the characteristic properties of secondary lymphoid tissue. ${ }^{26}$ No specific antigen has been successfully identified within the rheumatoid joint, though antigens may be sequestered in central or peripheral lymphoid tissue.

The predominance of $B$ cells in the activated populations in RA which we have shown in this 
study corresponds with the low incidence of $T$ cells in these fractions. The assay employed here for surface Ig detection would not have detected cytophilic IgG attached to $\mathrm{Fc}$ receptors ${ }^{27}$ or plasma cells in the later stage of their development, since these lose their surface $\mathrm{Ig}^{28}$ and thus the activated populations may contain more B cells than reported. Stimulation of purified $T$ cells with allogeneic lymphocytes produces no change in the detection of receptors for SRBC, ${ }^{29} 30$ which suggests a true representation by the $T$ cell levels reported in this study.

The increased EA binding in RA at low concentrations of erythrocyte coating IgG is in accordance with the data of Sharpin and Wilson, ${ }^{14}$ implying either increased numbers of Fc receptors or the presence of $\mathrm{Fc}$ receptors with high avidity binding to complexed IgG. Our observations of high avidity EA binding in the denser fractions, containing exclusively small lymphocytes, is suggestive of $\mathrm{K}$ cell activity in these fractions. ${ }^{31}$ As $\mathrm{K}$ cells are non-B, ${ }^{32}$ this could account for the distribution of high avidity $\mathrm{Fc}$ binding within the Ficoll gradient fractions.

We propose that in RA there is increased B cell activation of the blood lymphocytes and that there are increased numbers of non-B, non- $T$ lymphocytes possessing increased Fc-binding. Both abnormal populations could contribute to the pathology and persistence of joint damage in RA.

We are grateful to Anne Willington for secretarial assistance and to Ciba-Geigy for financial support (SDC).

\section{References}

1 Paulus H E, Machleder H I, Levine S, Yu D T Y, Macdonald N S. Lymphocyte involvement in rheumatoid arthritis. Studies during thoracic duct drainage. Arthritis Rheum 1977; 20: 1249-62.

2 Ueo T, Tanaka S, Tominaga Y, Ogawa H, Sakurami T. The effect of thoracic duct drainage on lymphocyte dynamics and clinical symptoms in patients with rheumatoid arthritis. Arthritis Rheum 1979; 22: 1405-12.

3 Hall J G, Smith M E. Homing of lymph-borne immunoblasts to the gut. Nature 1970; 226: 262-3.

4 Ishikawa Y, Ziff M. Electron microscopic observations of immunoreactive cells in the rheumatoid synovial membrane. Arthritis Rheum 1976; 19: 1-14.

5 Loewi G, Dorling J, Howard A. Mononuclear cells from inflammatory joint effusions : electron-microscopic appearances and immunoglobulin synthesis. $J$ Rheumatol 1974; 1: 34-44.

- Bacon P A, Sewell R L, Crowther D. Reactive lymphoid cells (immunoblasts) in autoimmune and haematological disorders. Clin Exp Immunol 1975; 19: 201-8.

7 Delbarre F, Le Go A, Kahan A. Hyperbasophilic immunoblasts in circulating blood in chronic inflammatory rheumatic and collagen diseases. Ann Rheum Dis $1975 ; 34: 422-30$.
8 Whaley K, Glenn A C A, Macsween R N M, et al. Immunological responses in Sjögren's syndrome and rheumatoid arthritis. Clin Exp Immunol 1971; 9: 721-31.

9 Van Boxel J A, Paget S A. Predominantly T cell infiltrate in rheumatoid membranes. $N$ Engl J Med 1975; 293: 517-20.

10 Ziff M. Relation of cellular infiltration of rheumatoid synovial membrane to its immune response. Arthritis Rheum 1974; 17: 313-9.

11 Utsinger P D, Bluestein H G. Sequential studies of T and B cells in RA and SLE. $J$ Rheumatol 1974; Suppl. 1 : 75.

12 Mellbye O J, Messner R P, DeBord J R, Williams R C. Immunoglobulin and receptors for $\mathrm{C} 3$ on lymphocytes from patients with rheumatoid arthritis. Arthritis Rheum 1972; 15: 371-80.

13 Brenner A I, Scheinberg M A, Cathcart E S. Surface characteristics of synovial fluid and peripheral blood lymphocytes in inflammatory arthritis. Arthritis Rheum 1975; 18: 297-303.

14 Sharpin R K C, Wilson J D. Increased EA rosette formation by lymphocytes from patients with rheumatoid arthritis. Clin Exp Immunol 1977; 29: 205-12.

15 Hall N D, Winrow V R, Bacon P A. Lymphocytes bearing $\mathrm{Fc} \gamma$ receptors in rheumatoid arthritis. I. An increased sub-population of cells in RA detected with Facb rosettes. Ann Rheum Dis in press.

16 Carter S D, Bacon P A, Hall N D. The isolation of activated lymphocytes from blood in discontinuous Ficoll density gradients. Submitted for publication.

17 Boyum A A. Isolation of lymphocytes, granulocytes and macrophages. Scand J Immunol 1976; 5 (suppl 5).

18 Shortman K, Haskill J S, Szenberg A, Legge, D G. Density distribution analysis of lymphocyte populations. Nature 1967; 216: 1227-9.

19 Gorczynski R M, Miller R G, Phillips R H. Homogeneity of antibody-producing cells as analysed by their buoyant density in gradients of Ficoll. Immunology 1970; 19: 817-29.

20 Steinman R M, Machtinger B G, Fried J, Cohn Z A. Mouse spleen lymphoblasts generated in vitro. Recovery in high yield and purity after flotation in dense bovine plasma albumin solutions. $J$ Exp Med 1978; 147: 279-96.

21 Metcalf W K, Ludwig S, Gould R N, Metcalf N F. The lymphocyte cytoplasmic refractive index in rheumatoid arthritis. Wadley Med Bull 1976; 6: 109-12.

${ }^{22}$ Surjan L Jr, Sebok J. Increase in intranuclear birefringence during chromatin activation reaction. Exp Cell Res 1973; 78: 241-3.

23 Papadimitriou G, Bacon P A, Carter S D, Hall N D. Rheumatoid immunoblasts-effect of gold and cyclophosphamide therapy. In: Willoughby D A, Giroud J P, Svartz N, eds. Inflammation-Mechanisms and Treatment. Lancaster: MTP Press, 1980: in press.

24 Feldbush T L, Steward N. Antigen modulation of the immune response. V. Generation of large memory cells in antigen draining lymph nodes. Cell Immunol 1978; 27: 336-45.

25 Parrott D M V, De Sousa M A B. Thymus-dependent and thymus-independent populations: origin, migratory patterns and life-span. Clin Exp Immunol 1971 ; 8: 663-84.

26 Yu D T Y, Peter J B. Cellular immunological aspects of rheumatoid arthritis. Semin Arthritis Rheum 1974; 4: 25-52.

27 Lobo P I, Westervelt F B, Horwitz D A. Identification of two populations of immunoglobulin-bearing lymphocytes in man. J Immunol 1975; 114: 116-9.

28 Takahasi T, Old L J, McIntre K R, Boyse E A. Immunoglobulin and other surface antigens of cells of the immune response. J Exp Med 1971; 134: 815-32. 
29 Jondal M. Surface markers on human B and T lymphocytes. IV. Distribution of surface markers on resting and blast-transformed lymphocytes. Scand J Immunol 1974; 3: 739-42.

30 Jondal M. Surface markers on human B and T lymphocytes. V. Characterisation of the lymphoproliferative response to three different lectins and allogeneic lympho- cytes by surface markers. Scand J Immunol 1974; 3: 749-55.

31 Sharpin R K C, Wilson J D. Studies on the nature of EA binding by lymphocytes from rheumatoid arthritis patients. Clin Exp Immunol 1977; 29: 213-9.

32 Perlmann P, Holm G. Cytotoxic effects of lymphoid cells in vitro. Adv Immunol 1969; 11 : 117-93. 